\title{
Design and Optimization of Proximity Coupled Antenna Using GA
}

\author{
Ruchi Varma ${ }^{1}$, Dr. Jayanta Ghosh ${ }^{2}$ \\ ${ }^{1}$ (ECE, National Institute of technology, Patna, India) \\ ${ }^{2}$ (Assistant professor, ECE, National Institute of technology, Patna, India)
}

\begin{abstract}
Microstrip antenna is gathering a lot of interest in communication systems. Genetic algorithm is a popular optimization technique and has been introduced for design optimization of proximity coupled antenna. Patch length, patch width are taken as optimization parameters. Return loss and radiation pattern for the optimized antenna are verified using IE3D software. Accuracy of the results encourages the use of genetic algorithm. Further a parasitic patch coupled to electromagnetically coupled microstrip antenna is designed for broadband operations using IE3D software
\end{abstract}

Keywords: Proximity coupled antenna, Genetic algorithm, broadband, IE3D.

\section{Introduction}

Microstrip antennas are used in a wide range of applications [2], but narrow impedance bandwidth often limits their more widespread use. The straightforward approach to improving bandwidth is increasing the thickness of the substrate supporting the microstrip patch. However, limitations still exist on the ability to effectively feed the patch on a thick substrate and radiation efficiency can degrade with increasing substrate thickness [3].

The electromagnetically (EM) coupled feed methods such as proximity coupling and aperture coupling can exhibit better bandwidth characteristics than traditional coaxial probe-fed and coplanar microstrip edge-fed methods due to the possibility of individual placement of the feed and patch on thin and thick substrates, respectively [1]. In this paper proximity coupled antenna is designed and optimized using genetic algorithm.

Planar, thin, light weight antennas are attractive for wireless applications. There are various types of wireless local area network (WLAN) standards, like, Bluetooth, Wi-Fi, Wi-MAX, High Performance LAN (HIPERLAN) etc. The objective is to design a broadband microstrip antenna for HIPERLAN. Here, the bandwidth is defined as the frequency range for which $\mathrm{S}_{11}$ is $-10 \mathrm{~dB}$.Thus in this paper length and width of proximity coupled antenna is optimized using genetic algorithm for impedance matching. Further a tuning stub in shunt with the microstrip feed line of the electromagnetically coupled microstrip antenna is designed for broadband operations using IE3D software.[7]

\section{Genetic algorithm}

Genetic algorithm is a robust global stochastic search methods based on the Darwinian concepts of natural selection and evolution. The parameters of each individual of the population are usually encoded as a string of bits (chromosomes). The first group of individuals (generation) is created randomly. The fitness of each individual is determined. Mating these individuals forms a new generation. The more fit individuals are selected and given greater chance of reproducing. The best individual may be passed unchanged to the next generation. This iterative process creates successive generations until a stop criterion is reached. It is expected that individuals of successive generations converge to the global maximum.[6],[7].

\section{Proximity Coupled Microstrip Antenna}

This type of feed technique is also called as the electromagnetic coupling scheme. Two dielectric substrates are used such that the feed line is between the two substrates and the radiating patch is on top of the upper substrate as shown in fig (1). The main advantage of this feed technique is that it eliminates spurious feed radiation and provides very high bandwidth due to overall increase in the thickness of the micro strip patch antenna. This scheme also provides choices between two different dielectric media, one for the patch and one for the feed line to optimize the individual performances. [4]. 


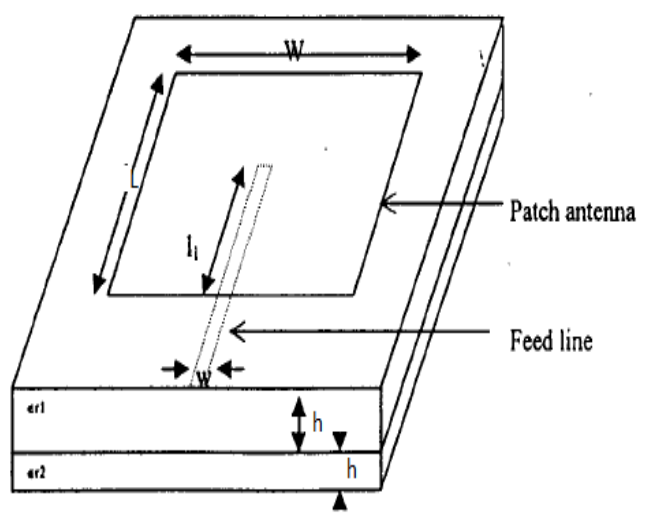

Fig:1: Proximity coupled antenna

In this paper, a microstrip antenna has been designed for HYPERLAN i.e. at a centre frequency (fr) of $5.5 \mathrm{GHz}$ with dielectric constant $\left(\varepsilon_{\mathrm{r}}\right) 4.36$ and substrate thickness $(\mathrm{h}) 1.6 \mathrm{~mm}$. The equivalent circuit for input impedance is given as below:

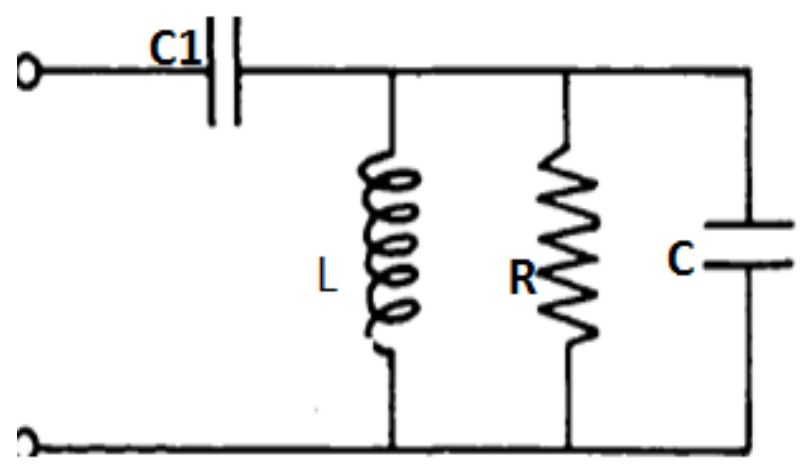

Fig 2: Equivalent ckt. Of input impedance

At this frequency we optimized the length and width of the antenna using genetic algorithm for impedance matching. The capacitance $\mathrm{C}$, is the coupling capacitance between the feed line and the patch antenna.[1]

$\mathrm{C}_{1}=\mathrm{wl}_{1} \epsilon_{0} \epsilon_{\mathrm{rl}} / \mathrm{t}_{1}$

The open ended feed line which is under the patch will have fringing fields, which can be considered as a small increase in the length of the feed line. This will have an extra capacitance. This effective increase in the length can be calculated using the formula

$1_{\mathrm{e}}=0.412 \mathrm{t}\left(\epsilon_{\mathrm{e}}+0.3\right)(\mathrm{w} / \mathrm{t}+0.264) /\left(\epsilon_{\mathrm{e}}-0.258\right)(\mathrm{w} / \mathrm{t}+0.8)$

where, $\epsilon_{\mathrm{e}}$ is the effective dielectric constant of the substrate, $w$ is the width of the line, and $t$ is the thickness of the substrate. If $1_{\mathrm{e}}$ is the extension in the effective length due to the fringing fields, then the fringing capacitance $\left(\mathbf{C}_{\mathrm{f}}\right)$ can be calculated using the formula.

$\mathrm{C}_{\mathrm{f}}=\mathrm{l}_{\mathrm{e}}\left(\epsilon_{\mathrm{e}}\right)^{-1 / 2} / \mathrm{cz}_{0}$

where $\mathrm{z}_{0}$ is the characteristic impedance of the line, and $\mathrm{c}=3 \times 10^{10} \mathrm{~cm} / \mathrm{sec}$.

At this frequency length and width of the antenna have been optimized using genetic algorithm for impedance matching. A MATLAB code has been written for the design of proximity coupled antenna. Using GA, two dimensional fitness function has been designed to find the length\& width of the antenna which is given below:

$\mathrm{F}=(\operatorname{abs}(\operatorname{real}(\mathrm{Z})-50+\operatorname{abs}(\operatorname{imag}(Z)-0)) / 2$

where $Z$ is an input impedance and $\operatorname{real}(Z)$ is the real part \& imag $(Z)$ is the imaginary part of $Z$.

Convergence graph for Genetic algorithm is obtained as shown in the figure below: 


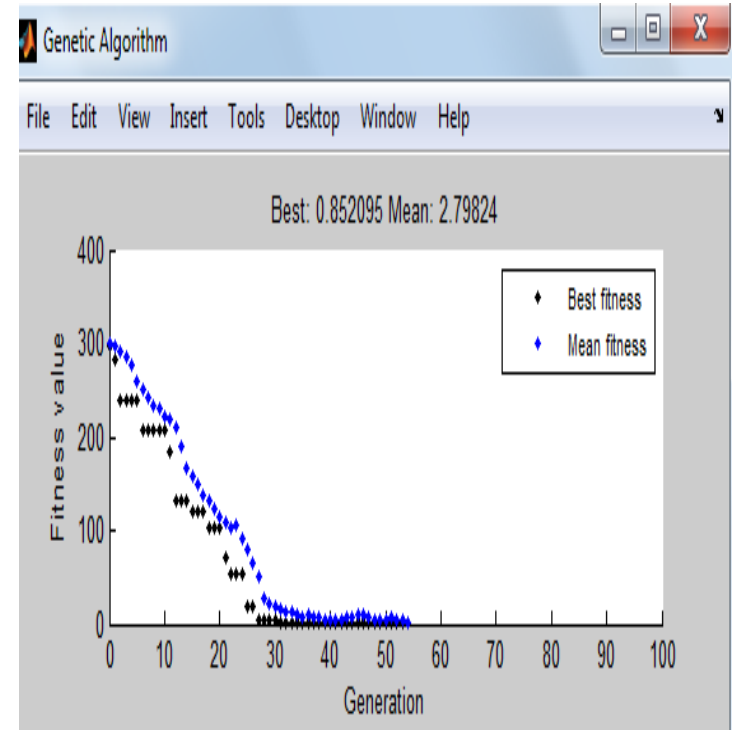

Fig 3: Convergence graph

In GA, we took the helpof MATLAB'S Global optimization tool box for this purpose:

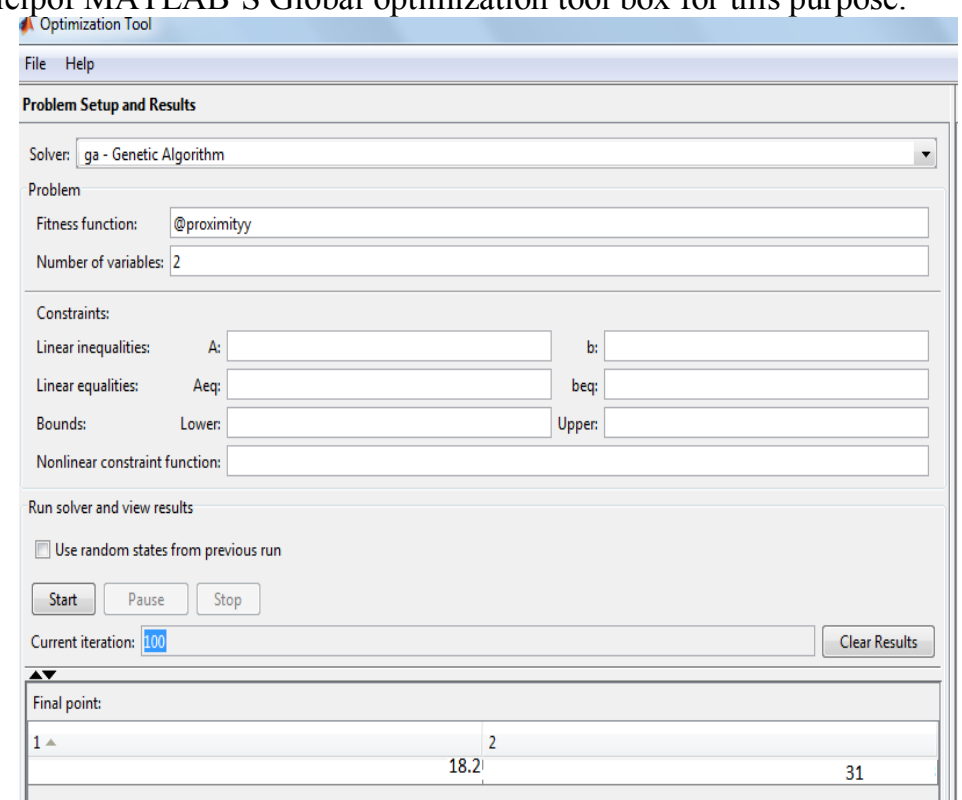

Fig 4: GA toolbox

The electromagnetically microstrip antennas are designed and the parameters are as follow:

Microstrip feed line width, $\mathrm{w}_{\mathrm{f}}=5 \mathrm{~mm}$

Microstrip feed line length, $\mathrm{l}_{\mathrm{f}}=15 \mathrm{~mm}$

Radiation patch with $\mathrm{W}=31 \mathrm{~mm}$

Radiation patch length $\mathrm{L}=18.2 \mathrm{~mm}$

\section{Simulation of optimized antenna}

Using IE3D a proximity coupled antenna operating for the frequency of $5.5 \mathrm{GHz}$ with dielectric substrate 4.36 and thickness $1.6 \mathrm{~mm}$ is designed and its $\mathrm{S}_{11}$ plot, Radiation pattern are as shown below: 


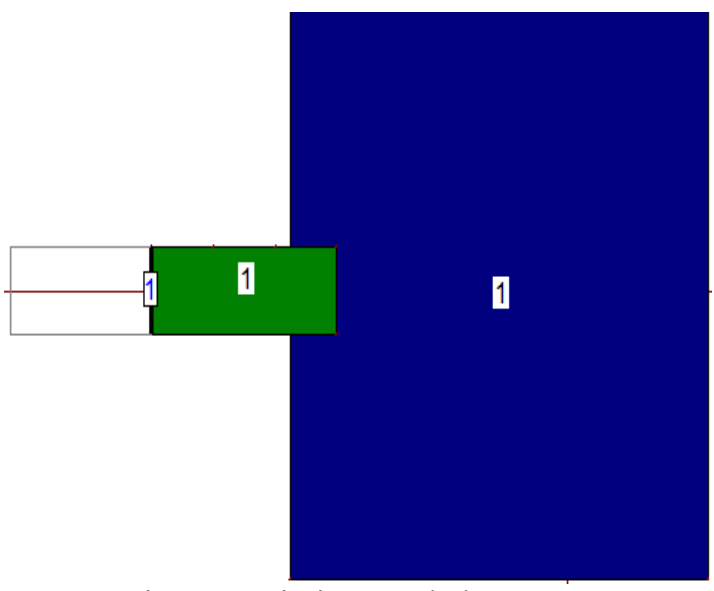

Fig 5: proximity coupled antenna

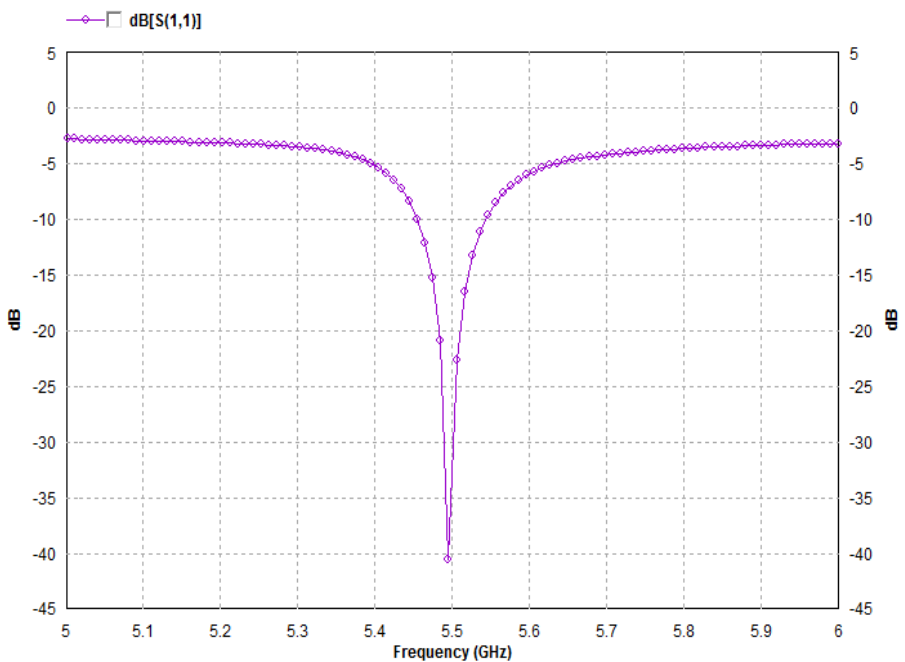

Fig 6: $\mathrm{S}_{11}$ plot

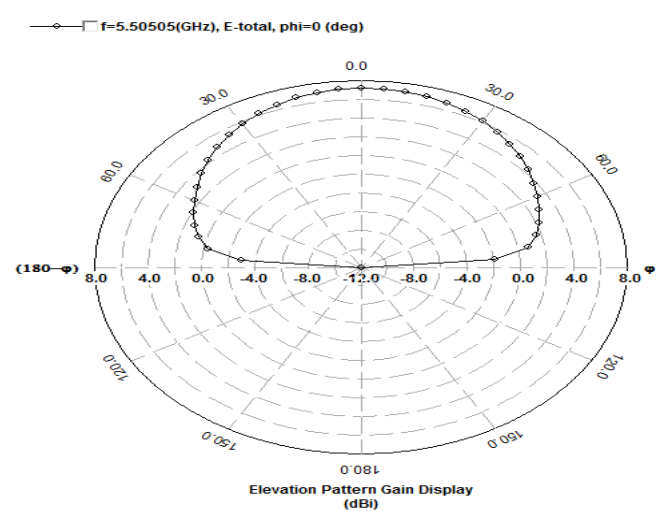

Fig 7: Radiation pattern

\section{BW enhancement using Parasitic patch}

Using IE3D a proximity coupled antenna operating for the frequency of $5.5 \mathrm{GHz}$ with dielectric substrate 4.36 and thickness $1.6 \mathrm{~mm}$ is designed using parasitic patch as shown in fig.

Microstrip feed line width, $\mathrm{w}_{\mathrm{f}}=5 \mathrm{~mm}$

Microstrip feed line length, $\mathrm{l}_{\mathrm{f}}=15 \mathrm{~mm}$

Parasitic patch length, $1_{\mathrm{s}}=4 \mathrm{~mm}$

Parasitic patch width, $\mathrm{w}_{\mathrm{s}}=10 \mathrm{~mm}$

Radiation patch width, $\mathrm{W}=31 \mathrm{~mm}$ 
Radiation patch length, $\mathrm{L}=18.2 \mathrm{~mm}$

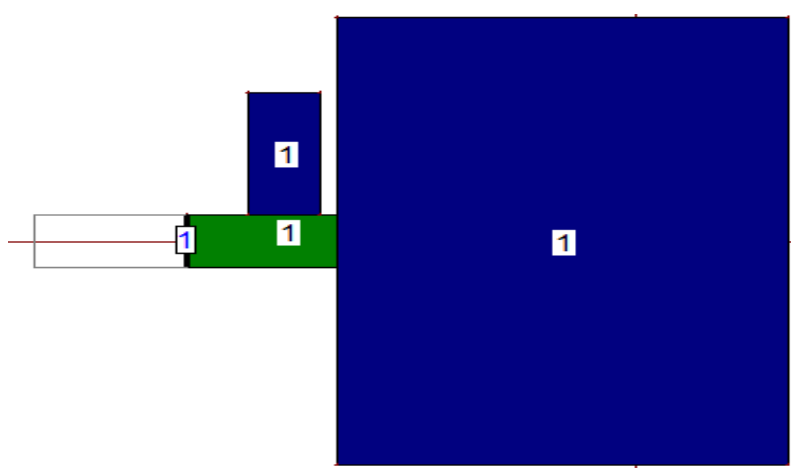

Fig 8: proximity coupled antenna with parasitic patch

\section{Results and Discussions}

The proximity coupled antenna is designed and simulated using IE3D software. A frequency range of $5-6 \mathrm{GHz}$ is selected and 100 frequency points are selected over this range to obtain accurate results. $\mathrm{S}_{11}$ is found to be $-38.7 \mathrm{~dB}$ and bandwidth of antenna is $90 \mathrm{MHz}(5.4533-5.5433 \mathrm{GHz})$.

From fig. 9 is significant the improved bandwidth of $8 \%$ in relation with the original $1.6 \%$ of the active patch.

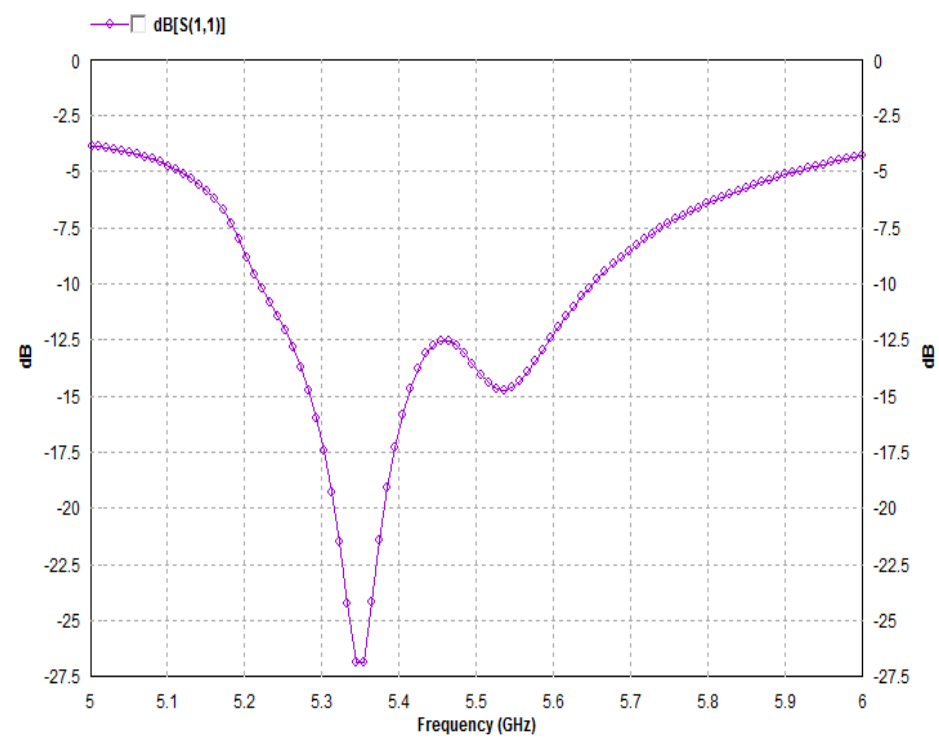

Fig 9: $\mathrm{S}_{11}$ plot with parasitic patch

\section{Conclusion}

In this thesis proximity coupled antenna is designed for HYPERLAN i.e. at a centre frequency $\left(f_{r}\right)$ of $5.5 \mathrm{GHz}$ and optimized using genetic algorithm. A MATLAB program is written for the design of proximity coupled antenna. After that the length and width of proximity coupled antenna is optimized using genetic algorithm where an impedance is perfectly matched to $50 \mathrm{ohm}$. The proximity coupled antenna is designed and simulated using IE3D software. $\mathrm{S}_{11}$ is found to be $-38.7 \mathrm{~dB}$ and bandwidth of antenna is $90 \mathrm{MHz}(5.4533-$ $5.5433 \mathrm{GHz})$.

Further a parasitic patch coupled to electromagnetically coupled microstrip antenna is designed for broadband operations using IE3D software. $\mathrm{S}_{11}$ is found to be $-11.25 \mathrm{~dB}$ and bandwidth increases to $430 \mathrm{MHz}$ $(5.22-5.65 \mathrm{GHz})$. 


\section{References}

[1] D. M. Pozar and D. H. Schaubert, Microstrip Antennas, The Analysis and Design of Microstrip Antennas and Arrays. New York: IEEE Press, 1995.

[2] G.A. Deschamps, 'Microstrip Microwave Antennas', Presented At The Third Usaf Symposium On Antennas, 1953.

[3] Constantine A. Balanis, 'Antenna Theory: Analysis Design', Third Edition, By ISBN 0-471-66782-X Copyright 2005 John Wiley \& Sons, Inc.

[4] R. Garg, P. Bhartia, I. J. Bahl, and A. Ittipiboon, Microstrip Antenna Design Handbook. Artech House(2001).

[5] R. L. Haupt and S. E. Haupt, Practical Genetic Algorithms. New York: Wiley( 1998).

[6] Y. Rahmat-Samii and E. Michielssen, Electromagnetic Optimization by Genetic Algorithms, Y. Rahmat-Samii and E. Michielssen, Eds. New York: Wiley, (1999).

[7] Siyang SUN, Y inghua LU, Jinling ZHANG, Fangming RUAN, Genetic algorithm optimization of broadband microstrip antenna 